\title{
FAMILIAL CONGENITAL STRIDOR
}

\author{
BY \\ HARRY V. L. FINLAY, M.B., Ch.B., M.R.C.P., D.C.H. \\ (From Hillingdon Hospital)
}

Almost a century has passed since Rilliet in 1851 described a case of stridor occurring in a young infant. This he presumed to be due to compression on the trachea by either a thyroid or thymic swelling. In 1853 Rilliet and Barthez in their classic French textbook on diseases of children were the first to describe as a clinical entity the condition which later came to be known as congenital laryngeal stridor.

Thirty years later Lees (1883) in Great Britain gave a description of a case of ' a peculiar form of obstructed inspiration,' in which examination by a laryngoscopic mirror previously had shown the aryteno-epiglottic folds to be close together and almost overlapping. Because the child had died of diphtheria, the larynx was examined post mortem. Lees claimed to be the first to describe the laryngoscopic appearances and post-mortem findings of such a case, and he stated that he had seen clinically a total of four cases with a similar condition. In the following year Gee (1884) described several instances of ' respiratory croaking of babies,' and made the observation that the disorder caused more annoyance to others than to the child.

The description of 'infantile respiratory spasm ' by John Thomson in 1892 helped to separate out a large group of cases of laryngeal stridor in young infants which ran a benign and self-limiting course.

In 1897 Sutherland and Lambert Lack described eighteen cases of 'congenital laryngeal obstruction,' of which six had been examined by a laryngeal mirror. In all of these, they noted the epiglottis sharply folded on itself, the two lateral folds being in close apposition. The aryteno-epiglottic folds were approximated, and thus the upper aperture of the larynx was reduced to a long narrow slit. The thin folds bounding the aperture 'flapped to and fro' on respiration. They were convinced that there was a valvular action of the upper aperture of the larynx, dependent partly on a peculiar congenital malformation in the anatomy of the larynx and partly on the flaccidity of these parts in infants. This is the view that is now widely held.

In collaboration with Logan Turner, Thomson presented a comprehensive description of this group in 1900. They described the classical picture of the child who developed noisy breathing shortly after birth. The stridor comprised a croaking sound which accompanied inspiration. Expiration was accompanied by a short croak when the stridor was loud, but at other times it was noiseless. There was no distress and no cyanosis. There was marked inspiratory indrawing of the thoracic and abdominal walls, except in the mildest cases. During the first few months of life the stridor increased in loudness as the child got stronger, but after remaining about the same for a few more months, it gradually lessened and disappeared during the course of the second year. Structurally there was an exaggeration of the peculiarities of the infantile larynx. They postulated an ill-coordinated, spasmodic action of the muscles of respiration as the primary cause, and the soft collapsible nature of the larynx as playing only a secondary part in the condition. They considered that the peculiar laryngeal deformity was thus purely an acquired one as the result of a nervous imbalance. While this view has not now many followers, Thomson's (1892) original clinical description of the condition could hardly be improved upon. Reardon (1907) reviewed the already fast growing literature on the subject. Thereafter the increasing use of direct laryngoscopy led to more accurate diagnosis in cases of infantile laryngeal stridor.

M'Kenzie (1925) described a case of severe congenital laryngeal stridor with dysphagia, aged three years, on whom a tracheotomy had to be performed, and he gave a critical review of the theories of the etiology of supra-glottic stridor. $\mathrm{He}$ reported observations made by Paterson using direct laryngoscopy. When Paterson held one side of the sucked-in margin of the laryngeal orifice with forceps, the noise stopped at once.

Although Variot had, a generation previously, suggested cutting away the aryepiglottic folds, Iglauer (1922) was apparently the first to undertake partial epiglottidectomy in a case of congenital laryngeal stridor, and he advocated this procedure in all such cases subject to asphyxial attacks.

Schwartz (1944) claimed to have taken the first coloured motion picture of the larynx during respiration in a case of congenital laryngeal stridor, and reproduced in his paper striking photographs from the film. He suggested the adoption of the term 'inspiratory laryngeal collapse,' and stressed the role of micrognathia as an etiological factor in these cases. He showed how the muscular and ligamentous forces concerned in the upper aperture of the larynx were affected by micrognathia. He 
carried out partial epiglottidectomy in one of his cases with relief of symptoms. One of his cases with both micrognathia and inspiratory laryngeal stridor had a brother also presenting both features.

Enlargement of the thymus is frequently stated to be an important cause of stridor in infancy. Kennedy and New (1931) reported from the Mayo Clinic a group of cases of chronic stridor in childhood. In fifteen of these cases, stridor was the chief complaint, but nine of these had been previously diagnosed as being due to thymic enlargement : eight out of nine had received $x$-ray treatment without benefit. Publishing a short series of illustrative cases, Trimby (1943) also has shown how rarely simple thymic enlargement is responsible for stridor or respiratory embarrassment in infancy.

The series of Bowman and Jackson (1939) of thirty consecutive infants, seen over a five-year period with chronic stridorous breathing, is of particular interest. Some degree of thymic enlargement was reported radiologically in twenty-one of these cases, but after careful investigation including $x$-ray examination, direct laryngoscopy, and bronchoscopy, the following diagnoses were made:

TABLE

\begin{tabular}{|c|c|}
\hline $\begin{array}{l}\text { No. of } \\
\text { Cases }\end{array}$ & Diagnosis \\
\hline 14 & $\begin{array}{l}\text { Supraglottic obstruction to inspiration due to deformity } \\
\text { or flaccidity of the epiglottis, arytenoids, and/or } \\
\text { aryepiglottic folds }\end{array}$ \\
\hline 5 & Enlarged thymus causing pressure on the trachea \\
\hline 2 & Hypertrophic laryngitis \\
\hline 1 & Web-like ridges in the subglottic area \\
\hline 1 & Thickening of one of the ventricular bands \\
\hline 1 & Congenitally small larynx \\
\hline 1 & $\begin{array}{l}\text { Cyst of thyroglossal duct with pressure of the tumour } \\
\text { from the base of the tongue upon the larynx }\end{array}$ \\
\hline 1 & Tuberculous bronchial lymph glands \\
\hline 1 & Micrognathia \\
\hline 1 & Collapse of part of the trachea \\
\hline 1 & Congenital beart disease \\
\hline 1 & Cause not found \\
\hline
\end{tabular}

This last series gives a rough idea of the relative frequency of the causes of chronic stridor in early infancy, and it emphasizes the need for routine chest $x$-ray investigation and direct laryngoscopy in all such cases. Thus approximately half the cases of chronic stridor encountered in infancy are due to ' inspiratory laryngeal collapse.'

There are many types of structural congenital anomalies of the larynx associated with stridor. Apart from the inspiratory collapse group, the most common of these is the presence of a membranous web joining the anterior ends of the vocal cords. A stenosis of the larynx as a whole is occasionally met, while cysts, haemangiomata, or papillomata are sometimes found to be the cause of the stridor, especially in older children. It is thus now becoming increasingly recognized that the term congenital laryngeal stridor embraces a considerable number of separate conditions.

The occurrence of three cases of laryngeal stridor in one family is considered to be of sufficient interest to warrant their publication. There have been four children in this family, all girls. All but one have been similarly affected with laryngeal stridor, and all those affected died.

A careful inquiry into the family pedigree on both the father's and the mother's side was made. There was no apparent consanguinity of the parents. The father, who was healthy, was an only child, but his parents were both from fairly large families. The mother, who suffered from bronchitis, was one of a large family, several of whom had children of their own. There was no traceable family history of ' throat trouble in infancy.'

\section{Case Reports}

P.B., the first child, was admitted to the London Hospital, E.1, on July 4, 1939, under Dr. A. G. Maitland-Jones for investigation.

The patient was born on May 14, 1939, at home by instrumental delivery. The birth weight was $4 \frac{1}{2} \mathrm{lb}$., and she was one month premature. She had difficulty in swallowing since birth. She took a long time over her feeds, and had choking attacks while taking them. On July 2, 1939, she went blue and collapsed while being fed.

On admission her temperature was $98^{\circ} \mathrm{F}$., and respirations 52 per minute. Definite stridor was present. She was fairly well nourished. The throat was normal on ordinary examination. No enlarged glands could be felt. Marked recession of the ribs on both sides was a feature. The percussion note was dull with a few crepitations at the right base. The heart, abdomen, and nervous systems were normal.

The child had various attacks of stridor while in the ward, and was tube-fed owing to the difficulty in feeding. She was distressed on coughing. Laryngoscopy was carried out under an anaesthetic. Shortly after the examination, the child's condition deteriorated with the development of pyrexia and marked dyspnoea. On the day following laryngoscopy, July 21,1939 , she died.

The post-mortem examination showed a fissure in the mid-line of the uppermost part of the posterior wall of the larynx, running down to the level of the cricoid and true vocal cords. The arytenoids were completely separated by the fissure. The true and false cords were not abnormal. The epiglottis seemed abnormally long.

A.B., the second child, was admitted to Hillingdon Hospital, Uxbridge, on Dec. 24, 1940, aged four days.

This infant, also a girl, was born at full-term on 
Dec. 21,1940 , at home. The history was that the child had been wheezy.

On admission it was found that there was no intercostal retraction when crying. The heart was normal. The chest was normal. The throat showed a highly arched palate with a very small entrance to the pharynx. Nothing abnormal was found in the abdomen or in the central nervous system. An extra toe was noted on the right foot. A radiograph of the chest on Dec. 30, 1940, showed normal aeration of both lungs.

Breast feeding was continued. When feeding or crying there was definite difficulty on inspiration, accompanied by crowing. The respirations were noiseless when the child was asleep. On Jan. 1, 1941, she was discharged home.

The child was readmitted to Hillingdon Hospital on March 13, 1941. All along she had gained weight slowly and during the two weeks before admission she had lost some weight and there had been a small amount of vomiting. On the evening of March 2, 1941, she had been coughing, and during the night she had had a choking fit, hence her readmission.

Examination on admission showed the general condition to be surprisingly good, and the child was taking feeds well. Laryngeal stridor was still noted, chiefly when crying. The chest was clinically clear.

On March 13, 1941, direct laryngoscopy was carried out by Mr. G. W. Duncan under general ether anaesthesia. A narrow glottis was seen with no evidence of polypi. The aperture was gently dilated. As a result of this dilatation, the cyanotic attacks ceased, although stridor was still present except when sleeping. The child however developed some degree of bronchitis, but the chest was clinically clear on discharge on April 6, 1941 .

She subsequently attended the out-patient department, but was readmitted on May 20, 1941, at the age of five months for further investigation and dilatation. The weight on admission was $9 \mathrm{lb} .15 \mathrm{oz}$. Laryngoscopy was carried out by Mr. L. Fatti on May 26, 1941, under general ether anaesthesia, and the report was: ' Larynx apparently normal, though small. No polypi visible.' The larynx was dilated.

On the same evening as the examination the child died suddenly after a convulsion, the cause of which was not clear.

The post-mortem examination by Dr. J. S. B. Bray showed a cyanosed child. The brain was normal. There was no abnormality of the heart. The lungs were oedematous. The larynx was stenosed in its upper portion.

B.B., the third child, also a girl, was born in Hillingdon Hospital on Oct. 21, 1942, with a birth weight of $7 \mathrm{lb}$., the birth being normal. In view of the previous family history, a careful watch was kept on the child, and it was noted on the case sheet, when the mother and child were discharged from hospital, that there had been 'normal respirations since birth without stridor.' No stridor developed and this child remains perfectly fit.

D.B., the fourth child, a girl, was born at home on Sept. 24, 1947, her birth weight being $6 \mathrm{lb}$. She was entirely breast-fed from the beginning, and the birth weight was regained by the fourteenth day.

The infant was first seen at the out-patient department of Hillingdon Hospital on Oct. 27, 1947, aged five weeks, having been referred to me by Dr. Kate Glyn-Jones. The mother had noted that the child seemed unable to cry loudly and had been hoarse. Otherwise the mother was not unduly worried. During the third week the child gained $3 \mathrm{oz}$., and during the fourth week gained $5 \mathrm{oz}$. on the breast. There had been no vomiting.

A general physical examination showed a small, puny infant. The head circumference was $13 \frac{1}{3}$ inches. The anterior fontanelle admitted three fingers. The cry was feeble. There was no clinical anaemia. No marked micrognathia was detected. Definite inspiratory laryngeal stridor was present without distress, but accompanied by slight indrawing of the chest wall. The heart sounds were normal and the chest clear. The abdomen was normal. The ears were dry. The throat was apparently clear.

A radiograph of the chest on Oct. 27, 1947, showed the lungs to be clear, but the bifurcation of the trachea was set at a more acute angle than normal. The child continued to attend the out-patient department regularly.

On Jan. 5, 1948, she was screened by Dr. S. A. Maddocks and a barium swallow was given. A right mid-zone pneumonic consolidation was present. The thymus was not enlarged radiologically. The trachea was of normal calibre, but there was apparently a marked laryngeal stenosis. There was no obstruction to the passage of barium down the oesophagus, but definite posterior notching of the oesophagus was noted. This suggested an aberrant vessel passing behind the oesophagus.

In view of the unhappy result of laryngoscopy in the two previously affected children, no attempt was made to examine this child by direct laryngoscopy. On Jan. 5, 1948, aged three months, she was admitted to Hillingdon Hospital. On examination she was found to be a very small child with a lusty cry. Continual mild stridor was present but the colour was good. The skull circumference was 14 inches. The anterior fontanelle admitted three fingers, and the skull bones were firm. The heart sounds were normal in all areas. The chest showed slight dullness on percussion over the right mid-zone posteriorly with occasional scattered rhonchi over both lungs. The throat showed relatively enlarged tonsils. The abdomen was poorly covered. There was no splenic enlargement. Neck rigidity was present, and the knee jerks both brisk.

The pneumonia was treated with both penicillin and sulphadiazine, and the child improved. Considerable head retraction remained constantly and typically present, the cerebrospinal fluid being normal. She was eager for her feeds, but tended to choke readily shortly after feeding had begun. Owing to repeated choking attacks feeding took a long time. 
On Jan. 15, 1948, the Kahn test was negative.

A further radiograph (Jan. 14, 1948) showed marked clearing of the pneumonic consolidation.

The child's general condition remained more or less the same until Jan. 28, 1948, when she developed a temperature of $102^{\circ} \mathrm{F}$., and became sunken and dyspnoeic. Another attack of pneumonia was suspected, and by Jan. 29, 1948, the percussion note was impaired over the left upper lobe anteriorly and there were many crepitations over the left lower lobe and in the left axilla. A few moist accompaniments were also present over the right base.

She went rapidly downhill and, in spite of treatment, died on Jan. 29, 1948.

NeCropsy : Cranium. The meninges were healthy, and there were no visible lesions in the brain. Mouth. The tongue was normal, as also was the pharynx. The thyroid was normal.

CHEst. The thymus was normal, and no adhesions or fluid exudates were present.

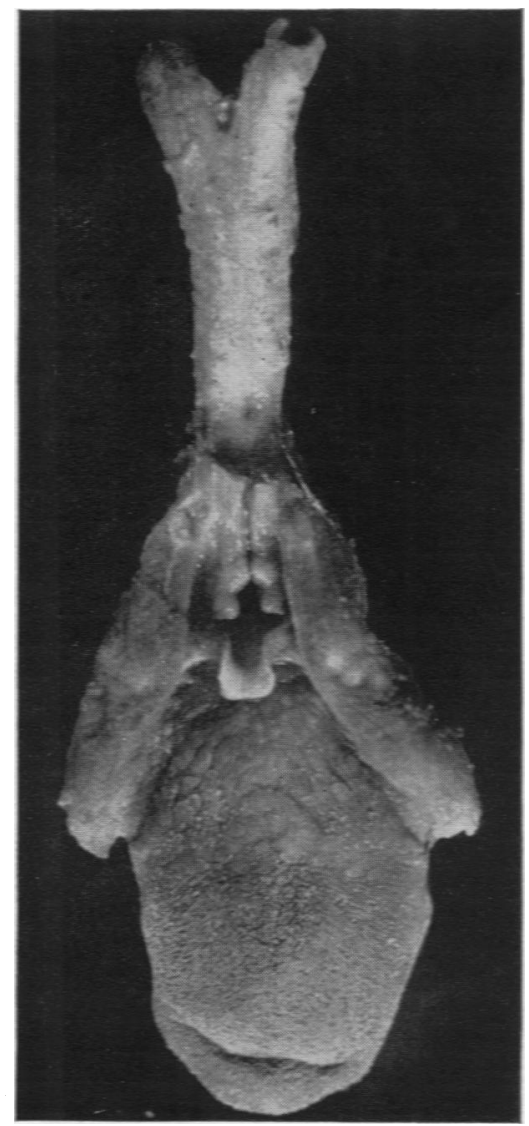

Fig. 1.-Larynx and trachea from the fourth child. The laryngeal aperture bas been widened by fixative action.

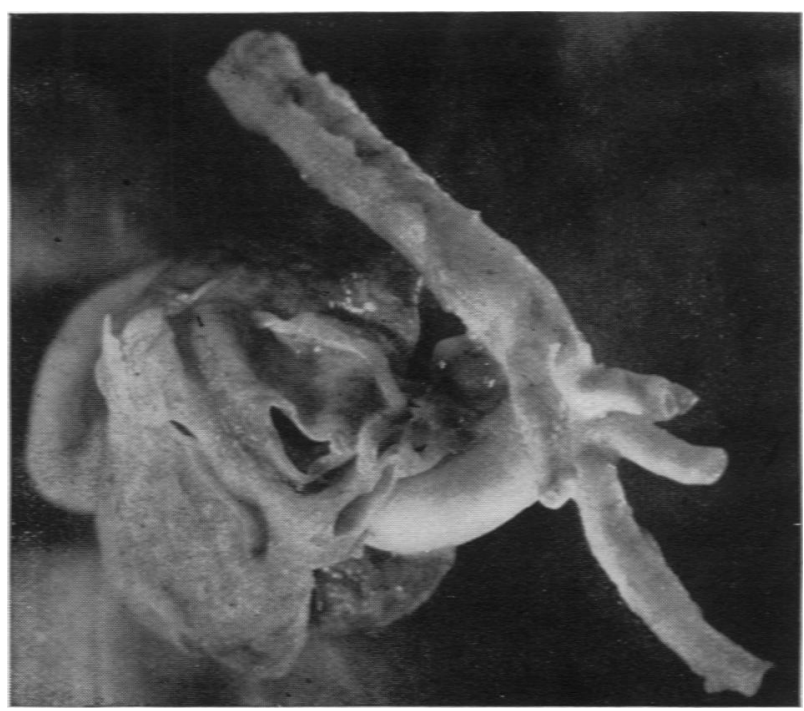

Fig. 2.-Aorta (posterior view) from the fourth child, showing the abnormal origin of the right subclavian artery.

LARYNX. The larynx as a whole was unduly narrow. The upper aperture was small, but there was no web or fissure present (fig. 1).

TRACHEA. The mucous membrane was normal. The bifurcation was an acute V-shape, and the primary bronchi somewhat lengthened. Both lungs contained areas of bronchopneumonia, and adjacent lung tissue was rather emphysematous in appearance. No caseous glands were seen and no evidence of tuberculosis found in the lungs.

Cardiovascular system. The pericardium was normal. The heart appeared to be normal and without congenital defects. The innominate artery did not divide and carried on upwards as the right carotid artery. The left carotid and left subclavian arteries were normal. From the descending thoracic aorta, a vessel arose at about the level of the second or third thoracic vertebra, and crossed the midline behind the oesophagus to run slightly upwards as the right subclavian artery (fig. 2). Below this level the aorta was quite normal.

AвDomen. The liver was slightly enlarged and toxic in appearance. The gall bladder and extrahepatic ducts were normal. The pancreas, adrenals, both kidneys, urinary tract, uterus, were all normal. The oesophagus was normal, as also the stomach, which contained a recent feed. In the intestine there was a short, broad Meckel's diverticulum.

Histological investigation showed in the lung a widespread bronchopneumonia with bronchioles full of polymorphic exudate; a congested liver with some toxic changes in hepatic cells, but biliary ducts healthy; in the kidney normal glomeruli with 
moderate degenerative changes in the epithelium of tubules. The pancreas was normal histologically.

The diagnosis was bilateral bronchopneumonia, with the associated defects of congenital narrowing of the laryngeal aperture, abnormal origin of the right subclavian artery of dysphagia lusoria type, and Meckel's diverticulum.

It was difficult to decide to what extent the abnormal origin of the right subclavian artery in the last child could account for the symptoms. This type of vascular anomaly can produce oesophageal pressure with resultant dysphagia but does not commonly, at any rate, produce stridor. There is no pulling forward of the trachea as is present when the trachea is completely encircled by a vascular ring, as in the double aortic arch anomaly. In the last case in this family the condition of the larynx was sufficient to account for the stridor.

It should be mentioned that an abnormal origin of the right subclavian artery may readily be missed, as indeed may any anomaly of the great vessels. During life a barium swallow is the means of detecting it and at necropsy its discovery entirely depends upon the technique employed in removing the thoracic contents.

Gross (1946) has reported what he believes to be the first case of dysphagia lusoria treated surgically This was an infant aged four months who presented with a history of difficulty in feeding. Examination of the oesophagus after swallowing barium showed indentation of the posterior oesophageal wall at the level of the third thoracic vertebra. Double ligation of an anomalous right subclavian artery near its aortic source was carried out, and after division between the ligatures the distal portion of the divided vessel was permitted to retract to the patient 's right and beyond the oesophagus. There was no further difficulty experienced with feeding after the operation. It should be noted, however, that there was no mention by Gross of stridor having occurred at any time in his case.

In a Moynihan Lecture, delivered in 1947, Blalock and Bahnson reporting a series of six hundred and ten cyanotic congenital heart cases operated upon, stated that in twenty-six of these there was a retrooesophageal subclavian artery. They mentioned that for some unknown reason these retro-oesophageal arteries were unduly thin-walled. In one patient in whom a retro-oesophageal subclavian artery was anastomosed to the pulmonary artery, there were suggestive signs of tracheal obstruction post-operatively owing to the vascular ring-created by the anastomosis.

\section{Summary}

Reference has been made to the more important papers illustrating the development of our knowledge of laryngeal stridor in early infancy.

The clinical notes and post-mortem findings of three children in one family, all showing congenital stridor, are presented.

The last case was shown to have an abnormal origin and course of the right subclavian artery. Two of the children died shortly after laryngoscopy.

I have to thank Dr. W. Arklay Steel, medical director of Hillingdon Hospital, for permission to publish this paper; I am much indebted to Dr. C. G. Barnes for his advice; and to Dr. A. G. Maitland-Jones for permission to quote from his notes regarding the first case.

I am grateful to both Dr. H. Rogers, who carried out the post-mortem examination in the last case, and Dr. W. R. May for their help and interest. The photographs are the work of Mr. E. A. R. Banks.

\section{REFERENCES}

Blalock, A., and Bahnson, H. T. (1948). Ann. R. Coll. Surg. Eng., 3, 57.

Bowman, J. E., and Jackson, C. L. (1939). J. Pediat., $15,476$.

Gee, S. (1884). St. Bart's Hosp. Rep., 20, 14-15.

Gross, R. E. (1946). Ann. Surg., 124, 532.

Iglauer, S. (1922). Laryngoscope St. Louis, 32, 56.

Kennedy, R. L. J., and New, G. B. (1931). J. Amer. med. Ass., 96, 1286.

Lees, D. B. (1883). Trans. path. Soc. Lond., 34, 19.

M'Kenzie, D., and Williamson, G. S. (1925). J. Laryng., 40, 285.

Reardon, T. J. (1907). J. Amer. med. Sc., 134, 242.

${ }^{*}$ Rilliet, F. (1851). Revue medico-chirurgicale.

Rilliet, F., and Barthez, E. (1853). Traité Clinique et Pratique des Maladies des Enfants. 2nd Ed., I, 485.

Schwartz, L. (1944). Arch. Otolaryng. Chicago, 39, 403.

Sutherland, G. A., and Lambert Lack, H. (1897). Lancet, $2,653$.

Thomson, J. (1892). Edinb. med. J., 38, 205.

-, and Logan Turner, A. (1900). Brit. med. J., 2, 1561.

Trimby, R. H. (1943). J. Amer. med. Ass., 122, 740.

*Variot, G. (1896). J. de Clin. et de Thérap. Infant, June $18,1896$.

(1898). Ibid., June 9, 1898.

* Original articles not read by the present writer. 